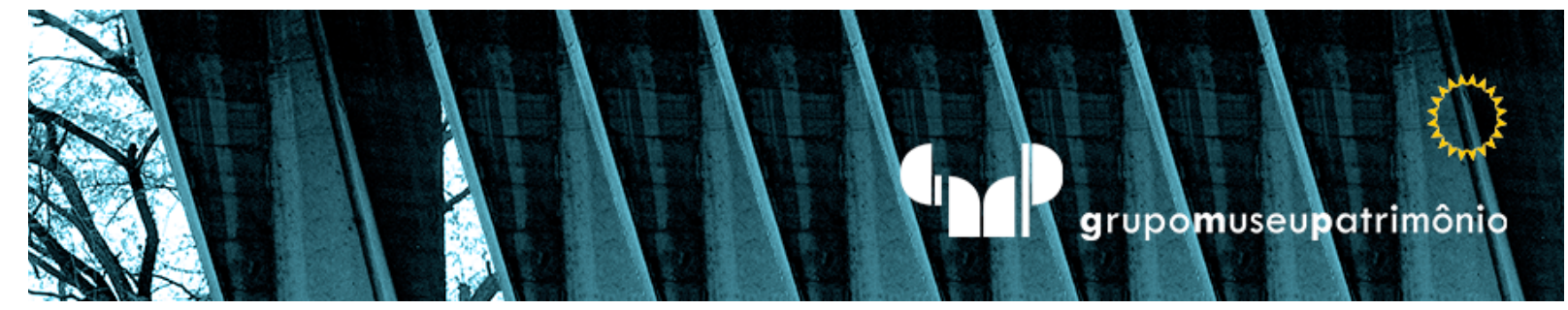

\title{
O artefato como dispositivo de profanação:
} reconstrução cultural no ideário Dadá e de Lina Bo Bardi

The artifact as a device of desecration: cultural reconstruction in the ideas of Dadá and Lina Bo Bardi

El artefacto como dispositivo de profanación: reconstrucción cultural en las ideas de Dadá y Lina Bo Bardi

Giancarlo Latorraca

Doutorando pelo Programa de Pós-Graduação da Faculdade de Arquitetura e Urbanismo da USP, Área de concentração - Design, São Paulo, Brasil. giancarlolatorraca@usp.br 


\section{Resumo}

O presente trabalho busca compreender aspectos ligados à profanação dos campos da arte e do design, expressos nos ideários do movimento Dadá e da obra de Lina Bo Bardi, a partir da apropriação simbólica de imagens e objetos do cotidiano, trazendo à luz novos procedimentos técnicos e plásticos que subverteram percepções pré-estabelecidas sobre a arte, os artefatos e os museus, como reação estética e política, vislumbrando uma revisão crítica da sociedade ocidental.

Palavras-Chave: Arte. Artefato. Design. Dadá. Lina Bo Bardi. Profanação.

\section{Resumen}

El presente trabajo busca comprender aspectos relacionados con la profanación de los campos del arte y del diseño, expresados en las ideas del movimiento Dadá y en el trabajo de Lina Bo Bardi, basadas en la apropiación simbólica de imágenes y objetos cotidianos, sacando a la luz nuevos procedimientos técnicos y plásticos que subvirtieron las percepciones preestablecidas sobre arte, artefactos y museos, como reacción estética y política, vislumbrando una revisión crítica de la sociedad occidental.

Palabras-Clave: Arte. Artefacto. Diseño. Dadá. Lina Bo Bardi. Profanación.

\section{Abstract}

This work aims to understand aspects related to the desecration of fields of art and design, expressed in the ideas of the Dadá movement and the work of Lina Bo Bardi, based on the symbolic appropriation of everyday images and objects, bringing to light new technical and plastic procedures that subverted predetermined perceptions about art, artifacts and museums, as aesthetic and political reaction, glimpsing a critical review of Western society.

Keywords: Art. Artifact. Design. Dada. Lina Bo Bardi. Desecration. 


\section{INTRODUÇÃO}

partir do conceito de profanação estabelecido por Giorgio Agamben,
para o qual profano[...]"em sentido próprio denomina-se àquilo que, de sagrado ou religioso que era, é devolvido ao uso e à propriedade dos homens" (AGAMBEN, 2007, p.58). Procura-se neste trabalho compreender as apropriações de imagens e objetos cotidianos propostas pelo movimento Dadá e por Lina Bo Bardi, que induziram à transmutação de seus valores de caráter simbólico e funcional, transformando-os em dispositivos profanatórios dos meios que passam a integrar, como objetos alheios e deslocados por ações contestatórias, representando em si a própria ruptura das estruturas culturais e políticas cristalizadas no campo da arte, dessacralizando-as.

A análise destas duas operações estéticas que buscavam a integração da arte com a vida, pensadas como saída para a transformação de valores políticos e culturais do século XIX e vislumbradas a partir de situações-limite de guerra mundial, parte da observação do deslocamento de objetos ordinários, (re) elaborados como "discurso manifesto" e visa identificar a pertinência, em ambos os casos, da proposição crítica ao consumo e à sociedade ocidental, levando em 
conta a relação intrínseca dos objetos como "uma rede de hábitos, ponto de cristalização de rotinas do comportamento" (BAUDRILLARD, 2000, p 101).

Podemos compreender estas as atitudes profanatórias, como uma reação à condição humana mais retrógrada associada a situações de guerra, mais especificamente das duas guerras mundiais, considerando a Primeira como evento detonador do "não movimento" Dadá e a Segunda como deflagradora de toda potência de reconstrução utópica que guiou de certa forma Lina Bo Bardi na diversidade de sua atuação. A transformação almejada pelo desafio das vanguardas, que buscaram reconstruir um outro mundo liberto dos cânones morais e negando o academicismo, foi o grande legado do primeiro movimento moderno, pontuado pelas Vanguardas Russas e pela Bauhaus, aqui consideradas como exemplos paradigmáticos na observação desse viés nas obras de Lina Bo Bardi e do Dadá, especialmente em sua vertente russa no período imediato pré e pós revolução bolchevique (1917).

O grupo de artistas Dadá apresentou novas práticas pensadas por meio de uma linguagem de ruptura e profanação dos meios, baseada na multiplicidade de experimentação em distintos campos artísticos que integravam a gênese de sua expressão plástica. Pelo manifesto inicial do dito "não movimento", com ironia jocosa, negava-se a sociedade corrompida pela guerra, a qual seus membros se recusaram a participar, inicialmente isolados na Suíça. Lina Bo Bardi por sua vez, teve sua trajetória marcada pela experiência da Segunda Guerra,

[...] marca que carregou durante toda a sua vida e de onde tirou, continuamente, forças para derrubar barreiras e reconhecer que a vida está sempre por um fio [...] Daí, Lina extraiu ao mesmo tempo seu profundo senso objetivo e poético (FERRAZ, 2011, p.48).

Assim, buscamos compreender qual teria sido o real papel de transformação no campo da arte, pela inserção inédita de artefatos como a fotografia e o objeto comum: o ready-made no caso do movimento Dadá e o objeto popular, no caso de Lina Bo Bardi, originalmente excluído do discurso do design ocidental como agente transformador. Consequentemente, procuramos também avaliar quais teriam sido as alterações decorrentes dessas operações 
no território "sacro" da arte, os Museus, considerando o seu crescimento quantitativo e aumento de representatividade social ao longo do século XX, em substituição às igrejas, como locais de "celebração de um mesmo culto", “incapaz de integrar a sociedade no seu conjunto" (POMIAN, 1985, p.84).

\section{NEGAÇÃo À BARBÁRIE - RECONSTRUÇÃO CRÍTICA DA SOCIEDADE OCIDENTAL}

Qué equivocación por parte de un hombre de guerra; tenemos también aquí un error al dirigir la fuerza devastadora no hacia las formas de la vieja cultura, sino hacia la destrucción de un cuerpo. Kazimir Malevich a Mijaíl Matiushin, 4 de abril de 1916 (1916 apud TUPITSYN, 2018, p.61).

A ação cultural-política que emerge em reação aos momentos de guerra, tidos como domínio da irracionalidade, embora apresentados como consequência racional da humanidade, é invariavelmente uma ação questionadora dos valores que constituíram o modelo de sociedade que acabou gerando a inconsequência humana da catástrofe. São postos em cheque paradigmas morais, culturais e estéticos, sem distinção, em uma proposta de revisão ética por meio de atuações de caráter universal, como as aqui observadas, que viabilizaram reflexões fundamentais de acesso crítico ao conhecimento coletivo, entre os campos da arte e do design.

As profanações anunciadas nos ideários Dadá e na obra de Lina convergem em sua origem histórica reativa a uma realidade arcaica, explicitada pela guerra. Ambas apontam para alguns alinhamentos comuns em reação à cultura burguesa estabelecida, manifestos de forma radical e com força de contestação pautada pela ironia e pelo absurdo, pela a ideia de repensar seus campos de atuação a partir de uma tabula rasa e pela a idealização de integrar a arte com a vida, assumindo uma postura "antiarte", contra a glorificação de uma arte e um design inatingíveis. Tratamos aqui visivelmente da superação 
dos paradigmas do século XIX frente à atuação política das vanguardas do século $\mathrm{XX}$, que incluiu, não com menor convergência, o construtivismo russo.

O ideário Dadá, que reflete em sua origem sobre a universalidade da condição de resistência proposta como redimensionamento ou reconstrução da sociedade moderna, implícita em sua negação estética e de signos (verbais e visuais), se apresentou como profunda recusa às estruturas simbólicas e à própria organização da sociedade, seus costumes e ideal de poder. O seu caráter 'transnacional' negava os princípios políticos nacionalistas, compreendidos como razão basal para o desenvolvimento das guerras e contestava a lógica e a estética até então estabelecidas por meio das linguagens consolidadas, abrindo novas possibilidades para o extenso campo de atuação das artes.

Os signatários do manifesto Dadá viviam em diferentes países como França, Estados Unidos, Espanha, Alemanha, Itália, Suíça e Bélgica, mas se autoproclamavam sem nacionalidade. Tendências Dadaístas, alinhadas à contestação da sociedade decadente e das formas artísticas superadas, logo surgiram em meio à vanguarda russa. ${ }^{1} \mathrm{~A}$ deflagração da guerra mundial em 1914 também havia afetado os russos e intensificou sua urgência em realizar a revolução cultural. Líderes de vanguarda como Kazimir Malevich, vislumbraram na guerra uma oportunidade para a "desintegração" do academicismo. Logo de início, produziu cartazes políticos contra a guerra, em colaboração com Vladimir Maiakovski, utilizando a linguagem das litografias populares (lubki) que com um tom de "zombaria implacável" característica

\footnotetext{
${ }^{1}$ A recente exposição Dadá ruso 1914-1924, organizada pelo Museo Nacional Centro de Arte Reina Sofía entre 6 de julho e 22 de outubro de 2018, vinculou a arte de vanguarda russa aos cânones do movimento Dadá internacional, apresentando importante fusão do ideário Dadá junto ao debate da arte não objetiva, pontuando o intercâmbio entre artistas Dadá de diversos países, sobretudo entre a Alemanha e a Rússia, desde o período da primeira guerra mundial, ressaltando a fundamental contribuição do movimento nas questões plásticas elaboradas no contexto da revolução bolchevique. O seminal cabaré Voltaire, sediado na Zurique que acolhia desertores, refugiados da guerra e conspiradores, chegou a ser frequentado por Lênin que esteve exilado na capital Suíça até 1917 (TUPITSYN, 2018, p.71).
} 
deste formato, mobilizava os camponeses para uma luta atroz contra a agressão alemã (TUPITSYN, 2018, p.61).

Paradoxalmente o movimento Dadá não se articulava da maneira programática como a arte que estava a serviço da revolução russa, assim como a obra de Lina lidava com aspectos da pratica construtiva, inerentes aos campos da arquitetura e do design, não menos programáticos e objetivos. Embora sejam aqui ressaltados aspectos teóricos em comum, há posturas distintas na mentalidade revolucionária Dadaísta entre a modernidade russa e a europeia. Sob a ótica da "execução da violência da forma artística", se russos e europeus coincidiram em suas abordagens contra a classe dominante (simbolizada no Dadá pelo exemplo máximo da obra Fontaine de Marcel Duchamp, de 1917), por um lado respirava-se "niilismo burguês e anarquismo", por outro, se buscava a "realização de problemas revolucionários" e sua conexão com os trabalhadores (TUPITSYN, 2018, p.69).

Lina, como descreve em sua própria experiência "entre bombas e metralhadoras" (BARDI, 1993, p.10), opta pelo caminho da "[...] objetividade e da racionalidade [...]"(BARDI, 1993, p.10), mesma senda da reconstrução necessária que logo se impôs aos territórios devastados, sob a égide do modernismo. Para ela "[...] um caminho terrivelmente difícil quando a maioria opta pelo 'desencanto' literário e nostálgico. Sentia que o mundo podia ser salvo, mudado para melhor, que esta era a única tarefa digna de ser vivida, o ponto de partida para sobreviver[...]" (BARDI, 1993, p.10).

Neste período, recomeçar do zero tinha também uma "[...] conotação política, da reconstrução social e cultural do país" (RUBINO, 2002, p.59) e representava um princípio comum às ações da primeira vanguarda, contextualizadas pela Primeira Guerra Mundial (1914 - 1918) e pela revolução russa (1917). Lina considerava viva a força motriz da vanguarda russa, como uma verdadeira vanguarda, cuja matriz inicial vimos ter sido "contaminada" pelo ideário Dadá no contexto das vanguardas internacionais. 
O moderno de hoje é ainda a vanguarda moderna de 1909 no campo existencial e no campo das artes plásticas. O grande esforço moderno da civilização ocidental ainda não se esgotou e ocidente está ainda comendo os restos de um grande capital. Depois de 60 anos, 70 anos, a vanguarda internacional verdadeira, russa, da França, internacional; não perdeu ainda a metáfora e é ainda hoje a verdadeira vanguarda (BARDI, 1993).

O período da reconstrução da sociedade pós-revolução russa foi marcado pela tentativa de operar no campo do ensino com desdobramentos práticos, por meio das Oficinas Superiores de Arte e Técnica (Vkhutemas 1918-1930), cujo projeto pedagógico interdisciplinar revolucionário, unia arte e técnica a serviço de uma nova construção social e buscava a formação de novos valores estéticos e culturais como ferramenta de transformação. Os princípios dessa experiência foram norteadores para a concepção da Bauhaus (1919-1933), que de certa forma a sucedeu. No momento do rescaldo da Segunda Guerra, outras forças econômicas e sociais operavam na retomada cultural e a ideia de um novo humanismo "anticomunista" despontava com a criação da Organização das Nações Unidas (ONU) e o Programa de Recuperação Europeia (Plano Marshall). Vkhutemas e Bauhaus já haviam sucumbido, uma, frente ao totalitarismo stalinista com a imposição do realismo socialista e a outra, frente ao nazismo ascendente na Alemanha de então.

Aspectos técnicos e facilitadores da vida associados à reconstrução, passavam por questões éticas fundamentais neste momento de revisão e no caso de Lina, sua procura almejava a necessária reação no campo das artes e consequente implementação do moderno na cultura da sociedade. Para ela, a guerra despertara o mundo europeu do sono das fantasias burguesas e iniciava a busca pelo utilitário desagregado dos valores supérfluos, das “vaidades inúteis do espirito humano" (BARDI, 1947, p.55). "A guerra destruiu o mito dos 'monumentos', também na casa, os móveis-monumentos não devem existir mais, também eles, em parte, entram na causa das guerras; [...]" (BARDI, 1947, p. 95). 
De certa forma, Lina Bo Bardi, sob a ótica da universalidade das rotas traçadas após o trauma da Segunda Guerra, manteve sempre uma postura crítica sobre a realidade, em busca contínua pela construção de outro mundo civilizado. Atuou com resistência, buscando novos modelos possíveis para dessacralizar os museus ${ }^{2}$ e a compreensão da arte, para que fosse entendida como prática do conhecimento técnico da humanidade através dos séculos, integrada à vida de todos os tempos. Expandiu o papel didático dos museus e organizou escolas de design a eles integradas: o Instituto de Arte Contemporânea (IAC, 19511953) no primeiro Museu de Arte de São Paulo (MASP) e a Escola de Desenho Industrial e Artesanato do Museu de Arte Popular da Bahia (1962-1963) em que enaltecia o valor da produção material de culturas alheias ao mundo do consumo e da "alta cultura", em um gesto profanatório ao campo do design.

\section{ARTE E ARTEFATOS COMO DISPOSITIVO DE PROFANAÇÃO}

O campo da arte pode ser aqui percebido tanto como território de prática profanatória, de contestação ao estabelecido cultural, social e político, bem como palco de negação à própria natureza definida à sua existência como arte em si. O Movimento Dadá internacional, que consideramos, sobretudo em seu momento de origem a partir de 1916, antes de sua derivação surrealista da década de 1920, expandiu seu afronte critico à sociedade por meio da arte, interagindo em extensão e sintonia com as propostas revolucionárias russas ${ }^{3}$. O Dadá incorporava o absurdo por meio das diversas linguagens que representaram sua atuação contestatória e performática, enfrentava a lógica

\footnotetext{
${ }^{2}$ Segundo Marcelo Ferraz, arquiteto com quem trabalhou por 15 anos, na concepção do MASP da Av. Paulista (1968), ela buscava a negação do Museu do séc. XIX, "Um museu sem paredes. Lina citava Maiakovski: 'Chegou a hora de jogar as pedras, os projéteis e as bombas nas paredes dos museus'” (FERRAZ, 2011, p.121).

${ }^{3}$ Entre vários pontos de intersecção, um contato efetivo se deu pela aproximação da vertente mais politizada do Dadá alemão com a Rússia, em que se destacam o Congresso de Construtivistas e Dadaístas em Weimar, 1922, suscitando uma "aliança entre construtivistas (leia-se não objetivistas) e Dadaístas" e a Primeira exposição de arte russa em Berlim no mesmo ano (TUPITSYN, 2018, p.131,132).
} 
vigente por meio da extrapolação do inconsciente, do uso da improvisação e da valorização irracional contra o racional.

Tanto o Dadá como Lina Bo Bardi convergem em sua postura contestatória sobre a aura institucionalizada da "obra" e seu status de autoria, apropriando-se de artefatos alheios ao universo da arte e do design, profanado estes territórios pela incorporação da fotografia e do objeto comum (o ready made), abrindo espaço para a ideia da arte sem cultura, da arte sem preconceito.

A ressignificação da imagem fotográfica representou uma frente contra a hegemonia da pintura e politicamente marcou o caráter de urgência e ruptura da época, especialmente em sua representação russa, cuja função "útil" da arte operava como instrumento revolucionário. As experimentações iniciais de Man Ray no campo da reprodução fotográfica ampliaram suas potencialidades técnicas e de expressão plástica, galgando espaços para novas simbologias e expressões artísticas que originalmente consideravam a fotografia como mero registro do real. A sua apropriação posterior como instrumento político, por meio das fotomontagens inicialmente produzidas pelo grupo Dadaísta de Berlim, ganha expressividade efetiva como objeto propagandístico no âmbito do "Construtivismo Fotográfico" russo (FABRIS, 2005).

As fotomontagens, compostas por colagens e composições gráfica inéditas, se destacaram pelas obras de Aleksandr Ródtchenko, El Lissitzky e Gustav Klutsis, tornando-se o meio de comunicação mais afeito à difusão dos novos valores culturais, como precursores da propagação de uma nova sociedade ${ }^{4}$. Foi uma linguagem potente para a difusão do ideal utópico, servindo como instrumento crítico e projetivo que permeou o ideário da arte e da arquitetura modernas

\footnotetext{
4 "A capacidade significativa e o grande potencial da fotomontagem para a arte política, estavam claros aos olhos tanto dos Dadaístas, que a consideravam 'um meio artístico Dadá', como aos artistas russos", que confirmaram esta linguagem como meio de expressão crítica à cultura e ao regime (TUPITSYN, 2018, p.85)
} 
posteriormente e, sobretudo, no segundo pós-guerra. Lina, em suas atividades gráficas e mesmo projetuais, lançou mão deste recurso inúmeras vezes ${ }^{5}$.

Na Itália, em 1946, a arquiteta participou da elaboração do semanário ACultura dela Vita, em parceria com o crítico Buno Zevi e o arquiteto Carlo Pagani, destinado a conscientizar a população dos problemas inerentes à reconstrução, apresentados como assunto de interesse coletivo, ressaltando a possibilidade efetiva de revisão de valores superados e acreditando na existência de um mundo melhor a ser construído. Extremamente politizada e com viés antropológico, a revista mapeava sob diversos aspectos as condições de vida precárias após o rescaldo da guerra, observando o modo encontrado pela população para viver entre ruínas, suas soluções técnicas e estratégias de sobrevivência. Abordava também temas emergentes com ampla abrangência: desde o surgimento da Bomba Atômica à problemática habitacional, da presença residual das minas terrestres ao planejamento familiar ${ }^{6}$.

Desta forma, os campos editorial e gráfico se evidenciam, em ambos os casos, como instrumentos de ação política comprometida com a reconstrução de uma nova sociedade, fato que tempos antes, na experiência russa, havia assumido um papel fundamental no contexto da revolução cultural, pela extensa difusão de cartazes, revistas e livros. ${ }^{7}$ Configuram-se, portanto, apropriações

\footnotetext{
${ }^{5}$ Em sua origem profissional na Itália, ela teve ampla experiência no campo editorial e gráfico, fato que lhe permitiu desdobramentos que foram fundamentais no Brasil como a revista Habitat e o caderno de cultura do Diário de Notícias de Salvador. Por meio do trabalho inicial no escritório de Gio Ponti, ela participou da organização das Trienais de Artes decorativas, escreveu artigos, editou e ilustrou jornais e revistas como Lo Stile (fundada pelo próprio Gió Ponti) e semanários populares como Tempo, Grazia e Vetrina, publicando propostas de ambientação e mobiliário para o leitor comum. Dirigiu a revista Domus, colaborou para o jornal Milano Sera e participou ativamente da elaboração da revista " $A$ ", junto com o crítico de arquitetura Bruno Zevi.

${ }^{6}$ Segundo Bruno Zevi, "[...]em nenhuma parte do mundo, nem antes de 1946, nem depois, houve uma revista semanal como $A$, na qual a arquitetura não fosse o escopo, mas o instrumento para compreender e mudar a vida; seminário de arquitetos, mas não de arquitetura, não para arquitetos" (ZEVI, 1992,s.p.).

7 A revista russa LEF, da "Frente Esquerda para as Artes", editada inicialmente por Osip Brik e Vladimir Maiakovski (1923 -1925) enaltecia o valor da nova arte a favor da revolução, destacando o papel coletivo dos artistas de vanguarda e teve importante papel na difusão desta nova linguagem. Publicada após o Congresso de Construtivistas e Dadaístas em Weimar em 1922, assumia a missão de unir os artistas progressistas para "formar uma frente de arte
} 
profanatórias dos potenciais plásticos da fotografia, que abriram novo espaço à manipulação da imagem como design de comunicação de massa.

O objeto comum profanou o território da arte acadêmica ao ser introduzido como dispositivo antiarte: um artefato pronto que, ressignificado para uma nova condição, tanto pelo seu deslocamento da função utilitária original como pelo acréscimo de partes, passa a ser enaltecido por sua "arte" ordinária, de técnica e construção anônimas, seja de natureza artesanal ou industrial. Desta forma, a "negação anarquista" dos Dadaístas "enfocou o desmantelamento da hierarquia e, consequentemente, a desestabilização de gêneros e convenções de arte". Os experimentos iniciais de Marcel Duchamp com os ready made, foram os mais representativos neste sentido, inclusive pelo frescor da ação de afronta, inserindo pela primeira vez objetos até então alheios ao espaço consagrado à arte, como Porte-bouteilles ou Hérisson (1914), En prévision du bras cassé (1915) e Fontaine (1917). Duchamp apagou as fronteiras entre "o trabalho intelectual e físico", transformando "radicalmente a prática artística" (PETROVA, 2018, p. 228,229).

Lina Bo Bardi profanou o território dos museus pela introdução pioneira da apresentação do artefato popular, a partir de uma ampla visão sobre a arte sem fronteiras das abordagens do primeiro MASP ${ }^{8}$. Esta "eliminação de barreiras" esteve presente entre outras exposições que organizou, sempre confrontando o saber popular versus o erudito no campo da arte. Posteriormente fez uso deste objeto comum, especificamente oriundo das soluções empíricas praticadas na elaboração de artefatos cotidianos pela cultura do Nordeste brasileiro, como dispositivo de profanação do campo do

\footnotetext{
esquerdista". A publicação de $n^{\circ} 2$, em inglês e alemão, trazia um editorial intitulado "Declaração: Camaradas modeladores da vida!" que estava marcado pelo "fervor político e antiartístico". No mesmo número, um texto do Dadaísta George Grosz sobre sua obra, destaca sua reflexão sobre a "mencionada aliança entre Dadaístas e construtivistas (não objetivistas)" (TUPITSYN, 2018, p.137).

${ }^{8}$ Sua primeira exposição de arte popular e ou artesanato apresentada no Museu de Arte foi a mostra Arte popular Pernambucana (1949).
} 
design. Em seu projeto para a Escola de Desenho Industrial e Artesanato do Museu de Arte Popular da Bahia (1962-1963), esta cultura material, vira pivô central da ideia de revolucionar o ensino do design, propondo redimensionar a natureza técnica, cultural e de produção e consumo de objetos, a partir da ideia de fusão entre o conhecimento autóctone e o científico ${ }^{9}$.

Esta busca representou seu o encontro entre a proposta inicial de síntese almejada pelo movimento moderno, conceitualmente abstrata, com a síntese formal e utilitária resultante das condições precárias de sobrevivência, associadas à consequente escassez de materiais e viabilizada pelo conhecimento técnico espontâneo. Assim, como na afronta Dadaísta do ready made, ela inseria no campo do design o objeto "sem cultura" justamente por operar fora do sistema de classificação, produção e consumo da sociedade capitalista. Sublinhava esta produção como resistência, "É a rede de Che-Guevara, são os 'buracos' e as flechas do Vietnã contra o requinte do mundo ocidental" ${ }^{10}$.

Em sua obra, o objeto catalisador que simboliza esta afronta ao establishment do mundo do design, é a cadeira de beira de estrada, criada em $1967^{11}$. Esta cadeira representa, à luz dessa análise, uma provocação Dadaísta de negação à própria natureza intrínseca do objeto e à essência do meio ao qual se inseria.

\footnotetext{
${ }^{9}$ Em entrevista ao Jornal do Brasil, em 1960, ainda no início de sua gestão no MAM-BA, ao refletir sobre os planos futuros do Museu, Lina menciona a ideia de uma escola que seria feita à partir do extenso levantamento de objetos oriundos da cultura material popular, cujo projeto promoveria a fusão entre saberes considerados técnicos especializados e aqueles identificados como espontâneos, conectando ambos à produção industrial: “... é nosso propósito lançarmos as bases de uma universidade de tipo popular, na qual seja possível um encontro fecundo entre os operários e os arquitetos, por exemplo, entre os executores de uma obra e seus criadores intelectuais. Reputo importante esse diálogo para que os operários compreendam claramente as ideias dos criadores e para que estes, por sua vez, tenham noção exata dos limites que a realidade impõe à criação artística" (RISÉRIO,1995, p. 236).

${ }^{10}$ Lina refere-se às redes de campanha utilizadas pela guerrilha organizada por Che-Guevara e às armadilhas que camuflavam buracos no solo preenchidos por flechas de galhos, usadas na luta dos vietcongs contra a invasão americana na Guerra do Vietnã. (BARDI,1994, p. 24)
}

${ }^{11}$ A arquiteta dedicou esta cadeira em homenagem ao cineasta Glauber Rocha, que havia colaborado com ela na exposição Bahia no Ibirapuera (São Paulo, 1959), no MAM Bahia (19591962) e com quem acompanhou em Monte Santo, Canudos (Bahia,1963) as filmagens de Deus e o Diabo na Terra do Sol, lançado em 1964, mesmo ano em que o golpe militar interrompeu abruptamente o projeto do Museu de Arte Popular do Solar do Unhão. 
Uma cadeira-manifesto, marcando o desapontamento e a perda da fé na "força regeneradora" do design; uma apropriação referente ao objeto ordinário, cuja simplicidade prescinde o domínio de conhecimento técnico específico consagrado pelo campo do design ; como se dissesse : para sentar, não é necessário muito malabarismo criativo e tantas especulações já feitas pelos designers neste tema. Sem excessos, sem soberba cultural nem formalismos estetizantes, apenas três pedaços de tronco amarrados por corda de sisal. Um "nada" inspirado em uma manifestação espontânea de origem africana, registrada no acervo de suas memórias (figuras 1 e 2).

Ela, que já havia desenvolvido séries de móveis junto ao arquiteto Giancarlo Palanti, no Studio de Arte e Arquitetura Palma (1948 a 1951), período em que foi produzida a icônica cadeira Bardi's Bowl (figura 3), a partir deste gesto contestatório, não voltou mais a produzir design com peças para consumo avulso. Desenhou somente peças intrinsecamente associadas à própria concepção arquitetônica de seus projetos ${ }^{12}$.

\footnotetext{
12 Desde então, a arquiteta criou mobiliário específico e de alta resistência para o teatro e restaurante do SESC Fábrica da Pompéia (São Paulo, 1982), desenhou os módulos 'caixotinhos' para as atividades infantis do mesmo projeto; a cadeira dobrável Frei Egydio, pensada para o público escolher seu lugar na composição da plateia do teatro Gregório de Mattos (Salvador, 1986), inspirado no teatro Nô Japonês; a cadeira girafa, concebida para o restaurante da Casa do Benin na Bahia (Salvador, 1987), entre outros.
} 


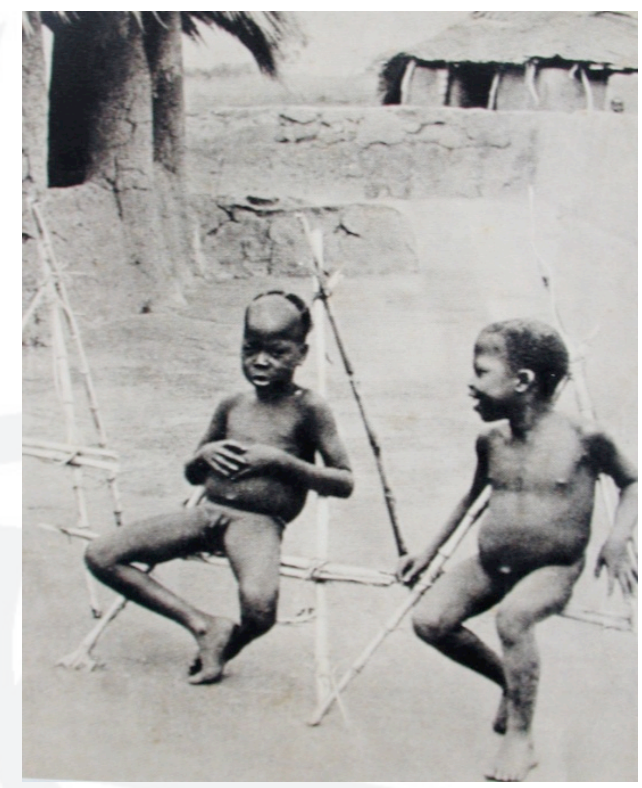

Figura 1: imagem sem descrição, coleção Lina Bo Bardi Fonte: Acervo Instituto Lina Bo e P.M. Bardi.

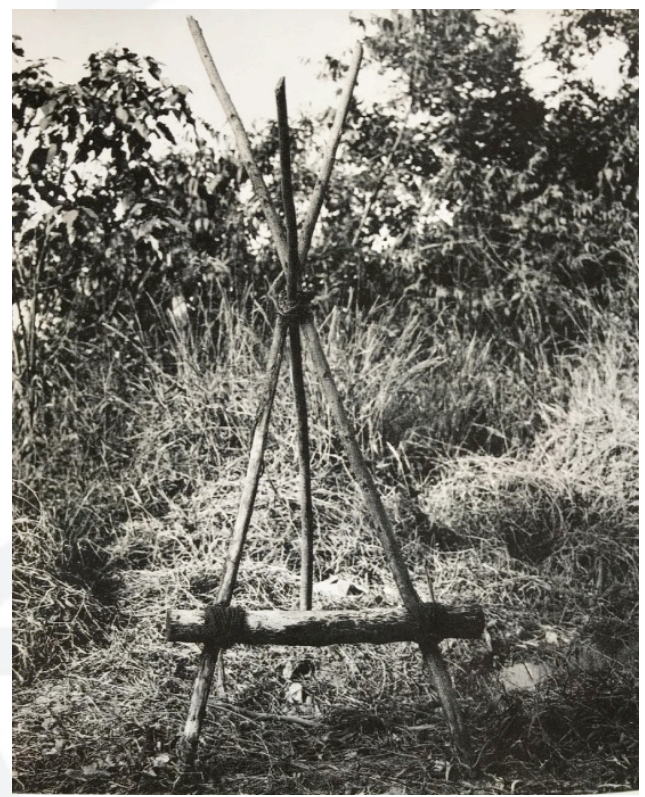

Figura 2: Cadeira de beira de estrada, 1967 Fonte: Acervo Instituto Lina Bo e P.M. Bardi. 


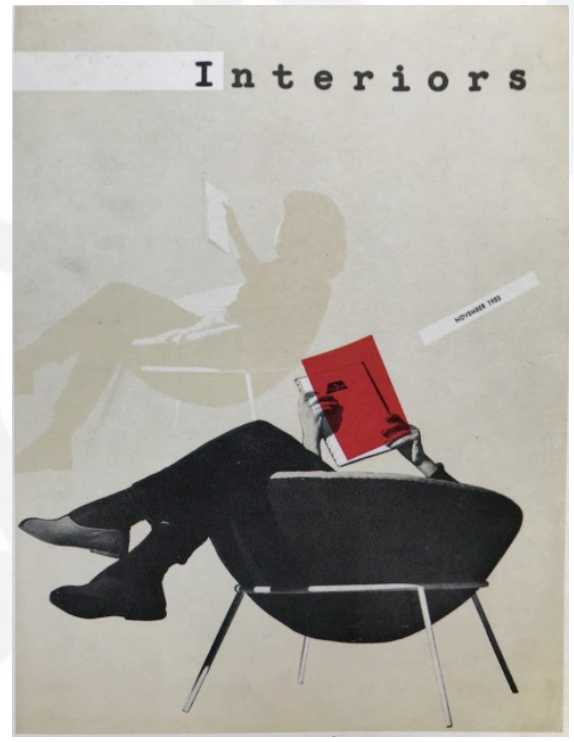

Figura 3: Cadeira Bardi's Bowl, capa revista Interiors, 1951 Fonte: Acervo Instituto Lina Bo e P.M. Bardi

\section{CONSIDERAÇÕES FINAIS}

A negação do museu tradicional, depositário de uma arte que já caminhava para romper sua expressão contida entre molduras ${ }^{13}$, foi também cavalo de batalha dessas distintas gerações. Para Lina Bo Bardi, uma ideia de novo museu pode ser viabilizada tempos depois na experiência do MASP (1968) da Av. Paulista. O meio expositivo, ou seja, os displays e sistemas projetados, configuraram uma desconstrução do discurso museológico tradicional em

\footnotetext{
${ }^{13}$ A arte, em sua trajetória própria que acabou historicamente por institucionalizar suas negações, desde a ruptura da tradição da pintura de cavalete anunciada neste período, seguiu sua expansão, em diálogo e/ou negação do espaço expositivo tradicional, passando a incorporálo como unidade. Foram seminais neste contexto, a Última exposição futurista de quadros: 0-10 apresentada em 1915 em São Petersburgo, em que Malevich expôs pela primeira vez o Quadrado Negro (TUPITSYN, 2018, p.42), a Primeira Feira Dadá Internacional, realizada em 1920 em Berlim, de caráter político extremo ao dependurar no teto a representação fiel de um militar alemão com cabeça de porco, e a pioneira instalação Merzbau de Kurt Schwitters, iniciada em 1923 em Hanôver. (O'Doherty 2002, p.41-47)
} 
busca de profanar o museu tradicional para libertá-lo das amarras consagradas como templo de sacralização da arte.

O cavalete de vidro, como display didático que alterou a condição do quadro, ou da pintura, de uma "janela na parede" para um objeto solto no espaço contemporâneo, sem classificação e simbolicamente aberto ao contato direto do observador, é seu o dispositivo profanatório mais evidente no campo dos museus. Ainda que este contato seja considerado simbolicamente, realizaria o que Agamben define como uma das formas mais simples de profanação, em que o simples toque, o "contágio profano", "desencanta e devolve ao uso aquilo que o sagrado havia separado e petrificado" (AGAMBEN, 2007, p.49).

De fato, profanações desta natureza não seriam factíveis, pois "a impossibilidade de usar tem o seu lugar tópico no Museu". Museu compreendido enquanto uma "dimensão separada para a qual se transfere o que há um tempo era percebido como verdadeiro e decisivo, e agora já não é" (AGAMBEN, 2007, p.65). Assim, observamos o objeto comum antes excluído da ordem artística e do campo do design, ordinário, ascender ao status de extraordinário.

Os experimentos Dadá acabaram por ser incorporados pelo sistema histórico das artes e celebrados pelo circuito dos museus; o artefato popular destacado pelas ações e mostras de Lina Bo Bardi, acabou por ser valorizado como produto excêntrico, adentrando o mercado de arte-popular, cujas intersecções com o campo do design acabaram restritas a apropriações formalistas e de caráter folclórico. O consumo indiscriminado de produtos e modelos importados, mais afeitos à economia mundial, se sobrepôs à estruturação de uma produção de design nacional. Portanto, paradoxalmente, a reestruturação de símbolos almejada, em ambos os casos observados, anulou-se no contexto da Arte Moderna e do Design Contemporâneo, cristalizando-se no campo dos museus, dispersa de sua natureza contestatória e incorporada pela hierarquia do poder hegemônico. 


\section{BIBLIOGRAFIA CITADA}

AGAMBEN, Giorgio. Profanações. São Paulo: Boitempo, 2007.

BARDI, Lina Bo. Na Europa a casa do homem ruiu, In: Rio, Rio de Janeiro, n.92, pp.53-55 e 95. fev. 1947.

BARDI, Lina Bo. Curriculum literário. In: FERRAZ, Marcelo (org.) Lina Bo Bardi. São Paulo: Instituto Lina Bo e P.M. Bardi, 1993.

BARDI, Lina Bo. Vídeo- documentário Lina Bo Bardi. MICHILIS, Aurélio; FERRAZ, Isa Grinspum, org. São Paulo: Instituto Lina Bo e P.M. Bardi, 1993. Transcrição do autor.

BARDI, Lina Bo. Tempos de grossura: o design no impasse. São Paulo: Instituto Lina Bo e P.M. Bardi, 1994.

BAUDRILLARD, Jean. O sistema dos objetos. São Paulo: Perspectiva, 2000.

FABRIS, Annateresa. Entre arte e propaganda: fotografia e fotomontagem na vanguarda soviética Anais do Museu Paulista. São Paulo. N. Sér. v.13. n.1.p. 99-132. jan. - jun. 2005.

FERRAZ, Marcelo. A poesia vital de Lina Bo Bardi. In: Arquitetura conversável. Rio de Janeiro: Azougue, 2011.

PETROVA, Olga Burenina. El anarquismo y la vanguardia artística rusa, In: TUPITSYN, Margarita. Dadá ruso 1914-1918 [cat. Exp., Museo Nacional Centro de Arte Reina Sofía, Madrid]. Madrid: Departamento de Actividades Editoriales del MNCARS, 2018.

POMIAN, Krzysztof. Coleção. Enciclopedia Einaudi Lisboa: Einaudi, 1985. Vol.I História-Memória.

RISÉRIO, Antonio. Avant-garde na Bahia. São Paulo: Instituto Lina Bo e P. M. Bardi, 1995.

RUBINO, Silvana Barbosa. Rotas da modernidade: trajetória, campo e história na atuação de Lina Bo bardi, 1947-1968. Tese de doutorado apresentada ao dep. De Antropologia do Instituto de Filosofia e Ciências Humanas da UNICAMP. Campinas, SP, 2002.

RUBINO, Silvana Barbosa; GRINOVER, Marina. Lina por escrito, textos escolhidos de Lina Bo Bardi. São Paulo: Cosac Naify, 2009.

TUPITSYN, Margarita. Situar a rusia em el mapa del dadá, In: Dadá ruso 1914-1918 [cat. Exp., Museo Nacional Centro de Arte Reina Sofía, Madrid]. Madrid: Departamento de Actividades Editoriales del MNCARS, 2018. 
ZEVI, Bruno. Lina Bo Bardi: Un architetto in tragitto ansioso. In: Caderno Lina, Caramelo, n. 4. São Paulo: Grêmio da Faculdade de Arquitetura e Urbanismo da Universidade de São Paulo, 1992.

\section{LISTA DE IMAGENS}

Figura 1: Aleksandr Ródchenko - desenho de capa para a revista LEF, no 2, 1923. Fonte: (TUPITSYN, 2018, p.89). - pág.: 204

Figura 2: Revista A - Cultura dela Vita (n.1, fev. 1946 e n. 9, jun. 1946).

Fonte: Acervo Instituto Lina Bo e P.M. Bardi. - pág.: 205

Figura 3: Cadeira Bardi's Bowl, capa revista Interiors, 1951

Fonte: Acervo Instituto Lina Bo e P.M. Bardi. - pág.: 205 